\title{
New challenges for clinical health psychology in diagnosis and therapy of tinnitus
}

\begin{abstract}
BACKGROUND
Tinnitus is becoming a social issue as the number of individuals suffering from this condition is still increasing. The aim of this study was to analyze the characteristics of tinnitus and related distress, as well as general distress of affected individuals.
\end{abstract}

\section{PARTICIPANTS AND PROCEDURE}

The study included 169 tinnitus patients aged between 22 and 88 years (mean 53.52). The duration of tinnitus ranged between 5 months and 30 years (mean 5.29 years). The participants presented either with normal hearing or with hearing loss. The study was based on a standardized interview and examination with two psychometric instruments: the General Health Questionnaire (GHQ-28) and the Tinnitus Handicap Inventory (THI).

\section{RESULTS}

Duration of tinnitus, its subjective severity, experiencing negative emotions and lack of social support turned out to be a composite measure determining the level of tinnitus-related distress. In turn, the level of distress was determined by sex of the participants, presence of difficulties in life, subjective severity of tinnitus and lack of social support.

\section{CONCLUSIONS}

Characteristics of tinnitus and its psychological consequences affect various functional aspects and health of the affected patients. The diagnostic instruments used in the study (THI and GHQ-28) proved to be appropriate and identified a subset of tinnitus patients who required appropriate psychotherapeutic intervention. The complex situation of patients experiencing subjective signs of tinnitus points to a necessity of cooperation between specialists in laryngology and psychologists, as a vital component of multidisciplinary evaluation and the therapeutic process.

\section{KEY WORDS}

tinnitus; role of clinical health psychology; diagnosis; therapy

organizations - 1: Laryngological Rehabilitation Center, Department of Otolaryngology, Poznan University of Medical Sciences, Poznan, Poland, 2: Department of Otolaryngology, Poznan University of Medical Sciences, Poznan, Poland, 3: Institute of Psychology, Adam Mickiewicz University, Poznan, Poland, 4: Department of Informatics and Statistics, Poznan University of Medical Sciences, Poznan, Poland

AUthors' CONTRIBUtion - A: Study design - B: Data collection - C: Statistical analysis - D: Data interpretation .

E: Manuscript preparation $\cdot F$ : Literature search $\cdot$ G: Funds collection

CORResPonding Author - Prof. Helena Sęk, Institute of Psychology, Adam Mickiewicz University, 89 Szamarzewskiego St., 60-658 Poznan, Poland, e-mail: shecel@amu.edu.pl 


\section{INTRODUCTION}

As both a theoretical and an applied science, clinical psychology utilizes and creates knowledge spanning various medical disciplines. In this context, psychological aspects of somatic disorders represent a particularly broad spectrum of problems (Heszen \& Sęk, 2007). The data on psychological risk factors for somatic disorders, psychological consequences of these conditions and their treatment are the subject
Monika Klepas,

Eugeniusz Szymiec, Helena Sęk, Zofia Obrębowska, Anna Sowińska of both research and practical application. Also the specific psychological situation of patients and their relationships with physicians and other members of the diagnostic and therapeutic team constitute vital aspects of clinical psychology. Clinical psychology of somatically affected individuals has found broad application in many medical disciplines, including cardiology, neurology, oncology, rheumatology, and pediatrics. This refers mostly to chronic conditions and the so-called psychosomatic disorders. The role of psychologists in these specialties is well defined and established, and their achievements considerable.

However, still new challenges emerge and require the definition of rules of cooperation between psychologists and physicians. In our opinion, such cooperation represents a compromise between the expectations of physicians and patients and the abilities of psychologists. A psychologist is always required to understand the specifics of a new medical discipline and identify related problems. One of the new medical challenges is tinnitus, a condition from the field of otolaryngology.

Tinnitus is becoming a social issue as the number of individuals suffering from this condition is still increasing. It is estimated that between $20 \%$ (Pajor, Józefowicz-Korczyńska, Durko \& Ormezowska, 2009) and $28.3 \%$ of individuals from the Polish population (Fabijańska, 1998) suffer from tinnitus.

Tinnitus is a subjective ${ }^{1}$ acoustic phenomenon of variable severity and duration. It can be persistent or periodical, either barely perceptible or so severe that it precludes normal everyday functioning. Also the consequences of tinnitus may vary and are usually individual-specific; the condition may hinder the patient's ability to concentrate on performed tasks, and disturb falling asleep and relaxing (Robert \& Dobbie, 2004). Furthermore, as an unknown and thus threatening phenomenon, tinnitus may give rise to a number of health concerns (Erlandsson \& Hallberg, 2000; Solly \& Erlandsson, 2000). Tinnitus may manifest as various sounds, registered in the head, or heard by one or both ears simultaneously. Subjective severity of tinnitus may alter due to irritation, fatigue, fluctuations of atmospheric pressure, changes in body position or exposure to noise (Bartnik \& Borawska, 2002). Sometimes the tinnitus is so "strange" and burdensome that it requires psychiatric consultation.
The causes and determinants of tinnitus are highly complex (Bartnik \& Borawska, 2002). Tinnitus is typically associated with cochlear injury resulting from acoustic shock, exposure to loud noise, infection or influence of ototoxic agents. Other causes of tinnitus include vascular or hormonal disorders and mechanical injuries of the head and ear. Also exposure to stress and difficult life situations play an important role in the etiopathogenesis of this condition.

A number of publications have addressed various aspects of tinnitus. These are usually interdisciplinary, theoretical rather than empirical, publications, e.g. a paper published by J. B. Snow (2004), entitled "Tinnitus Theory and Management". Moreover, several excellent textbooks addressed to various specialists dealing with tinnitus, e.g. a book edited by Richard Tyler (2000), entitled Tinnitus Handbook, have been published to date. The latter textbook comprises 19 chapters, including as many as four chapters written by psychologists: on the psychological profile of tinnitus patients, various psychotherapeutic approaches, and organization and functioning of self-support groups for tinnitus patients (Reich, 2000). Moreover, the abovementioned R. Tyler (2008) edited a monograph entitled The Consumer Handbook on Tinnitus, in which physicians, psychologists, audiologists and specialists in neuroscience shared their experiences in explaining the phenomenon of tinnitus and management of patients with this condition. The Australian psychologists Henry and Wilson (2001) published a guide for patients with tinnitus, entitled Tinnitus: A Self-Management Guide for the Ringing in Your Ears. Furthermore, recently published studies, conducted both abroad (Zeman, Koller, Langguth, Landgrebe \& Tinnitus Research Initiative database study, 2014) and in Poland (Zielińska-Bliźniewska \& Olszewski, 2009), dealt with the quality of life and incidence of depression among tinnitus patients.

Consequently, the issue of tinnitus seems to be extensively explored and well known, as such not representing a new challenge for psychologists. However, the abovementioned findings from studies conducted abroad, frequently outside Europe, require cross-cultural adaptation to Polish conditions. Furthermore, we still lack evidence obtained with new research methods, as well as formation of Polish interdisciplinary research, diagnostic, therapeutic and rehabilitation teams.

All these activities were undertaken by Dr. Eugeniusz Szymiec and his colleagues from the Laryngological Rehabilitation Center at the Poznan University of Medical Sciences. The group included a psychology consultant, Prof. Helena Sęk from the Institute of Psychology, Adam Mickiewicz University (AMU) in Poznan, as well as another psychologist from AMU, Monika Klepas, MSc, as a permanent member of the team. It was decided that the role of a psychologist in the team would be defined in the course of a research 
program aimed at psychological characterization of tinnitus patients treated at the center. Also the results of previous Polish research on tinnitus-related distress and the effect of this condition on general status and quality of life of affected individuals (Kałużny, Durko \& Pajor 2005; Kotyło, Macheta \& Śliwińska-Kowalska, 2009), incidence of emotional disorders among tinnitus patients (Kałużny, Durko, \& Pajor, 2004; Pajor et al., 2009) and efficiency of psychological intervention in this group (Kotyło, Merecz, Niebudek-Bogusz \& Śliwińska-Kowalska, 2006) were considered. The role of cooperation between physicians and psychologists during rehabilitation of tinnitus patients was also highlighted by Karpiesz, Latkowska, Sarnictwa and Bartnik (2012) from the World Hearing Center.

The principal aim of this paper is to utilize the results of previous research conducted by the Laryngological Rehabilitation Center team (Klepas, Szymiec, Sęk, Sowińska \& Obrębowska, in press) for developing general theoretical foundations for further studies of psychological determinants and consequences of tinnitus, and application of this knowledge in psychological diagnosis and therapy. Therefore, the following research questions were formulated: What is the level of tinnitus-related distress and what are the problems experienced by the affected patients? What is the level of distress of tinnitus patients? Do the characteristics of tinnitus (duration, lateralization, hearing threshold) modulate the distress related to this condition and general distress of affected patients? Do presence of comorbidities and/ or difficulties in life (life stress), age, sex and educational level of patients exert a significant effect on the level of tinnitus-related distress and general psychiatric distress? Nevertheless, the key question derived from the results of previous studies was: How can this knowledge be improved and applied to everyday research, diagnostic and psychotherapeutic practice?

\section{PARTICIPANTS AND PROCEDURE}

The study included individuals who started treatment at the Laryngological Rehabilitation Center at the Poznan University of Medical Sciences. The study group was comprised of 169 patients, 76 women (44.97\%) and 93 men (55.3\%) aged between 22 and 88 years (mean 53.52). The duration of tinnitus ranged between 5 months and 30 years (mean 5.29 years). The patients represented a variable educational level; the group was predominated by individuals with secondary (43.20\%) and higher education (33.73\%). The participants presented either with normal hearing $(n=63$, $37.87 \%)$ or with hearing loss $(n=103,60.95 \%)$. Two persons $(1.18 \%)$ were unable to declare whether they heard normally. The study group varied in terms of subjectively perceived lateralization of tinnitus. Most patients $(46.15 \%)$ experienced bilateral tinnitus; more rarely, the source of tinnitus was localized in the head $(12.43 \%)$, and $2.37 \%$ of the respondents were unable to localize the source of their ailment. The subset of patients with unilateral tinnitus included $23.67 \%$ and $15.38 \%$ of persons in whom the condition affected only the left and only the right ear, respectively.

The study began with a clinical interview. After explaining a purpose of the visit, the patients were asked about their perception of tinnitus and related distress, duration of the ailments, and ways of coping with them. Moreover, the participants were asked about potential comorbidities, difficulties in life and sources of social support. Demographic data and medical information on the tinnitus and other health-related problems were obtained from a physician in charge and/or extracted from the records of audiological examination. During the psychological examination, the patients were asked to complete the scale of tinnitus severity, in which 0 corresponded to lack of any ailments, and 10 to unbearable tinnitus.

Two questionnaires that were used during recent Polish studies of tinnitus patients (Kałużny et al., 2005; Kotyło et al., 2009; Kotyło et al., 2006; Pajor et al., 2009) were chosen for the purpose of psychometric evaluation. The choice of the questionnaires was based on an analysis of literature resources. One selection criterion was the possibility of comparing obtained results with available data from previous Polish studies and studies conducted abroad. Also the possibility of conducting future evaluation studies was considered. Finally, we looked for questionnaires that were suitable for serial examination, thus enabling changes taking place in the course of the therapy to be monitored.

The effect of tinnitus on overall functioning of the patients was determined using the Tinnitus Handicap Inventory (THI), developed by Newman, Jacobson, and Spitzer (1996). Both the theoretical background and the instrument itself are aimed solely at examination of tinnitus patients. The inventory includes 25 questions divided into three subscales: emotional responses, functional (social, occupational, physical and psychological) disorders, and catastrophizing (Robinson et al., 2003). Answers to the questions included in the THI reflect the degree of tinnitus-related distress. The questions included in the emotional subscale refer to an array of affective responses of tinnitus patients. In turn, the questions included in the "catastrophizing" scale describe the most serious reactions to the condition (Aksoy, Firat \& Alpar, 2007; Snow, 2004). The questionnaire has been the subject of many adaptations and is characterized by highly satisfactory psychometric parameters, e.g. Cronbach's $\alpha$ of .93 (Henry et al., 2006).

The level of distress was determined with the General Health Questionnaire developed by David Goldberg (GHQ-28). The questionnaire, in the Polish adaptation by Zofia Makowska and Dorota Merecz (2001), determines the level of mental health of adult
Health psychology and tinnitus 
Monika Klepas,

Eugeniusz Szymiec, Helena Sęk, Zofia

Obrębowska, Anna Sowińska persons. However, it should be remembered that the instrument is not a positive measure of mental health but is rather oriented at assessment of risk for mental disorders. The longer version of the instrument contains 28 questions, grouped into four subscales: hypochondriasis, anxiety, social impairment and depression. Apart from its accuracy, we selected this instrument as it was previously used for examination of patients with tinnitus (Kałużny et al., 2004; Kotyło et al., 2009; Kotyło et al., 2006). The GHQ-12 and GHQ-28 user manual comprises two parts: Polish translation of the original instrument and a comprehensive description of the adaptation procedure. Moreover, the authors of the Polish adaptation, Makowska and Merecz (2001), refer to the results of validation studies and, what is particularly valuable, present Polish reference values for the scale. According to the manual (op cit.), the reliability of the questionnaire, expressed by Cronbach's $\alpha$, is .934 for the global score and .766-.901 for the subscale scores.

\section{RESULTS}

We found that in $55.03 \%$ of the patients tinnitus was not an isolated ailment, but co-existed with other somatic disorders, such as arterial hypertension, diabetes mellitus, psoriasis, glaucoma or neoplasm. In contrast, tinnitus was rarely associated with the presence of a mental disorder (in $14.20 \%$ of the patients). Some of the participants declared having various difficulties in life, resulting from emotional (44.97\%), familial (19.53\%), occupational (10.65\%) and economic problems $(1.78 \%)$ or other issues $(9.47 \%)$. However, it is noteworthy that a considerable fraction of the patients did not report any significant problem, probably due to low severity and/or short duration of tinnitus. Therefore, the issue of potential problems should be discussed carefully with tinnitus patients; the questions should be open-ended and non-suggestive.

A total of $89(52.66 \%)$ participants declared using individual ways of coping with tinnitus. The patients tried to avoid staying in silence by listening to music, undertook physical activity, and distracted their attention from tinnitus by involvement in other activities. Most patients $(81.07 \%)$ reported obtaining social support; $1.78 \%$ of the respondents did not require any support from others.

Our patients differed markedly in terms of subjective severity of tinnitus, scored on a scale from 0 to 10 . The scores ranged between 0.5 and 10 points. It is noteworthy that 30 persons $(17.75 \%)$ were unable to assess the subjective severity of their ailments.

The mean score of the Polish version of the Tinnitus Handicap Inventory (THI) was 41.66, and mean levels of mental health determined with GHQ-28 were 26.50 for the global score and 7.79, 7.86, 8.04 and 2.81 for scales A, B, C and D, respectively. Detailed scores of both instruments are presented in Table 1.

The THI scores reflected considerable variation in the degree of tinnitus-related distress experienced by our participants. In the largest fraction of patients (30.77\%), the THI scores corresponded to mild distress; $26.04 \%$ of the participants experienced moderate distress, and $17.75 \%$ only a slight distress or complete lack thereof. Individuals who experienced severe tinnitus-related distress corresponded to $25.4 \%$ of the study group. Consequently, we identified these 43 persons as requiring particular attention and care. Detailed data on the THI scores are presented in Table 2.

Analysis of results obtained with the General Health Questionnaire (GHQ-28) documented high and moderate scores in $40.83 \%$ and $37.28 \%$ of the examined group, respectively; individuals with low scores represented the smallest fraction (21.89\%). Such distribution of the scores suggests that as many as $78.11 \%$ of our patients were at increased risk of distress. Therefore, also subjects with moderate tinnitus-related distress seemed be prone to development of mental disorders; however, further research is needed to explain this issue. Detailed data on the GHQ-28 scores are presented in Table 3.

We conducted an analysis of regression to explain which of the analyzed variables determined the degree of tinnitus-related distress. Duration of tinnitus, its sub-

Table 1

Descriptive results of the Tinnitus Handicap Inventory (THI) and Global Health Questionnaire (GHQ)

\begin{tabular}{lcccc}
\hline \multicolumn{1}{c}{ Measures } & $M$ & $S D$ & Min. & Max. \\
\hline THI global & 41.66 & 24.31 & 0.0 & 98.0 \\
GHQ global & 26.50 & 12.85 & 7.0 & 71.0 \\
GHQ somatic symptoms scale A & 7.79 & 4.23 & 0.0 & 21.0 \\
GHQ anxiety and sleepless scale B & 7.86 & 4.56 & 0.0 & 21.0 \\
GHQ functional disorders scale C & 8.04 & 2.89 & 0.0 & 20.0 \\
GHQ depression scale D & 2.81 & 3.83 & 0.0 & 18.0 \\
\hline
\end{tabular}




\begin{tabular}{lcccccc}
\hline & \multicolumn{2}{c}{ Female } & \multicolumn{2}{c}{ Male } & \multicolumn{2}{c}{ Summary } \\
\cline { 2 - 7 } & $n$ & $\%$ & $n$ & $\%$ & \multicolumn{2}{c}{$n$} \\
\hline Slight or no handicap - Grade 1 & 8 & 4.73 & 22 & 13.02 & 30 & 17.75 \\
Mild handicap - Grade 2 & 25 & 14.79 & 27 & 15.98 & 52 & 30.77 \\
Moderate handicap - Grade 3 & 21 & 12.43 & 23 & 13.61 & 44 & 26.04 \\
Severe handicap - Grade 4 & 15 & 8.88 & 12 & 7.10 & 27 & 15.98 \\
Catastrophic handicap - Grade 5 & 7 & 4.14 & 9 & 5.33 & 16 & 9.47 \\
Summary & 78 & 44.97 & 93 & 55.03 & 169 & 100.00 \\
\hline
\end{tabular}

Health psychology and tinnitus jective severity, experiencing negative emotions, presence of comorbidities and difficulties in life, and lack of social support explained together $53 \%$ of variance in the dependent variable $\left(R^{2}=.53\right)$, i.e. the score of the Tinnitus Handicap Inventory. Therefore, the vast majority of independent variables analyzed in our study turned out to play a significant role as determinants of the tinnitus-related distress. Subjective severity of tinnitus $(\beta=0.61)$ and duration of this condition $(\beta=0.13)$ proved to be significant predictors of the THI score.

Also the other dependent variable, i.e. the level of mental health determined with GHQ-28, was subjected to regression analysis. It showed that $35 \%$ of variance $\left(R^{2}=.35\right)$ in the dependent variable was explained by the combined effect of such variables as sex, presence of comorbidities and difficulties in life, subjective severity of tinnitus, and lack of social support. Subjective severity of tinnitus $(\beta=0.24)$, sex ( $\beta=0.21)$, availability of social support $(\beta=0.16)$, presence of comorbidities $(\beta=-0.21)$, and occupational $(\beta=-0.29)$ and economic problems $(\beta=-0.17)$ turned out to be significant predictors of psychological distress diagnosed with the General Health Questionnaire (GHQ-28).

Consequently, we identified other determinants of distress than only subjective severity of tinnitus. This points to an important problem of distinguishing between the determinants of tinnitus-related distress and the determinants of general distress.

\section{DISCUSSION}

We found that the studied group of patients was highly heterogeneous in terms of the analyzed variables: age, duration of tinnitus, its severity and health consequences. Moreover, our patients experienced other health-related problems and difficulties in life that might influence the levels of their general psychiatric distress and tinnitus-related distress.

The mean score of the Polish version of the THI in our group turned out to be lower than the values documented in similar studies conducted abroad (Aksoy et al., 2007; Figueiredo, Azevedo \& Oliveira Pde, 2009). In turn, the mean level of psychiatric distress was similar to those reported by other authors dealing with tinnitus patients (Kotyło et al., 2009; Kotyło et al., 2006; Pajor et al., 2009). The fact that more than three fourths of our patients were at increased risk for distress is an important finding in the context of both future research and clinical practice, as it points to the necessity of developing psychotherapeutic and prophylactic programs adjusted to the needs of this group. The cognitivebehavioral approach to this problem is advocated in the literature (Kotyło et al., 2009; Kotyło et al., 2006; Tyler, 2000, 2008).

Analysis of regression identified subjective severity of tinnitus (scored on a scale from 0 to 10 ) as the main determinant of the THI score and psychiatric

Table 3

Results of the Global Health Questionnaire

\begin{tabular}{lcccccc}
\hline \multirow{2}{*}{ Sten } & \multicolumn{2}{c}{ Female } & \multicolumn{2}{c}{ Male } & \multicolumn{2}{c}{ Summary } \\
\cline { 2 - 7 } & $n$ & $\%$ & $n$ & $\%$ & $n$ & 21.89 \\
\hline Low & 21 & 12.43 & 16 & 9.47 & 37 & 37.28 \\
Medium & 30 & 17.75 & 33 & 19.53 & 63 & 40.83 \\
High & 25 & 14.79 & 44 & 26.04 & 69 & 100.00 \\
Global & 76 & 44.97 & 93 & 55.03 & 169 & \\
\hline
\end{tabular}


Table 4

Multiple regression analysis for the dependent variable tinnitus - THI

Summary of the regression model

\begin{tabular}{|c|c|c|c|c|c|}
\hline \multicolumn{6}{|c|}{$\begin{array}{c}\text { Summary of the regression model } \\
R=.73, R^{2}=.53, \text { Adjusted } R^{2}=.49, \text { Std. error } 18.01, F=14.35, p<.001\end{array}$} \\
\hline Parameters & $B$ & $\begin{array}{l}\text { Std. } \\
\text { error }\end{array}$ & $\beta$ & $t$ & $p$ \\
\hline Duration of tinnitus & 0.55 & 0.27 & 0.13 & 2.07 & .04 \\
\hline Negative emotions & -6.13 & 3.27 & -0.12 & -1.87 & .06 \\
\hline Subjective severity & 6.94 & 0.75 & 0.61 & 9.31 & .00 \\
\hline Comorbidities & -0.51 & 3.23 & -0.01 & -0.16 & .87 \\
\hline Mental disorders & -2.92 & 4.57 & -0.04 & -0.64 & .52 \\
\hline Life difficulties & 1.98 & 4.11 & 0.03 & 0.48 & .63 \\
\hline Job difficulties & -9.11 & 4.91 & -0.12 & -1.68 & .07 \\
\hline Financial difficulties & -27.58 & 11.65 & -0.16 & -2.37 & .02 \\
\hline Social support & 1.63 & 3.47 & 0.03 & 0.47 & .64 \\
\hline
\end{tabular}

Table 5

Multiple regression analysis for the dependent variable global health - GHQ-28

\begin{tabular}{lccccc}
\hline \multicolumn{5}{c}{ Summary of the regression model } \\
\multicolumn{1}{c}{ Parameters } & $B$ & $\begin{array}{c}\text { Std. } \\
\text { error }\end{array}$ & $\beta$ & $t$ & $p$ \\
\hline Sex & 0.84 & 0.31 & 0.21 & 2.75 & .01 \\
Severity of tinnitus & 0.22 & 0.07 & 0.24 & 3.04 & .00 \\
Comorbidities & -0.84 & 0.29 & -0.21 & -2.86 & .01 \\
Mental disorders & -0.60 & 0.43 & -0.11 & -1.41 & .13 \\
Life difficulties & -0.75 & 0.38 & -0.15 & -1.98 & .05 \\
Job difficulties & -1.83 & 0.45 & -0.29 & -4.03 & .00 \\
Financial difficulties & -2.31 & 1.01 & -0.17 & -2.28 & .02 \\
Social support & 0.71 & 0.32 & 0.16 & 2.21 & .03 \\
\hline
\end{tabular}

distress level. A similar relationship was documented in previous studies analyzing associations between the THI score and the results of the visual analogue scale (Figueiredo et al., 2009). Consequently, one should consider further improvement of this simple measure as a diagnostic tool of tinnitus-related distress. Although the factors analyzed in our study as potential determinants of tinnitus-related distress and general distress seemed to be appropriately chosen, they did not explain all the variance in these dependent variables (53\% and $35 \%$ of variance in tinnitus-related distress and general distress, respectively). According to the literature (Tyler, 2000), apart from laryngological ailments, the abovementioned dependent variables can also be modulated by patient personality, considered both as a resource and a risk factor, as well as by environmental conditions and level of life stress. Moreover, some authors (Tyler, 2008) have pointed to individual strategies of coping with tinnitus as a potential determinant of related distress. Analysis of relationship between tinnitus-related distress and personality traits and/or disorders is particularly challenging as the latter complex factor may constitute both a cause and a consequence of tinnitus. Therefore, the abovementioned relationship is likely bidirectional. Furthermore, implementation of a variable constituting a positive measure of mental health, or a relatively short, reproducible measure of subjectively perceived quality of life, would be justified from a therapeutic perspective (Kałużny et al., 2005).

On the basis of literature data and the results of our study, the theoretical foundations for future research can be presented as a model of interrelated variables, as shown in Figure 1.

The results of previous studies point to the established role of the variables that are presented in the 


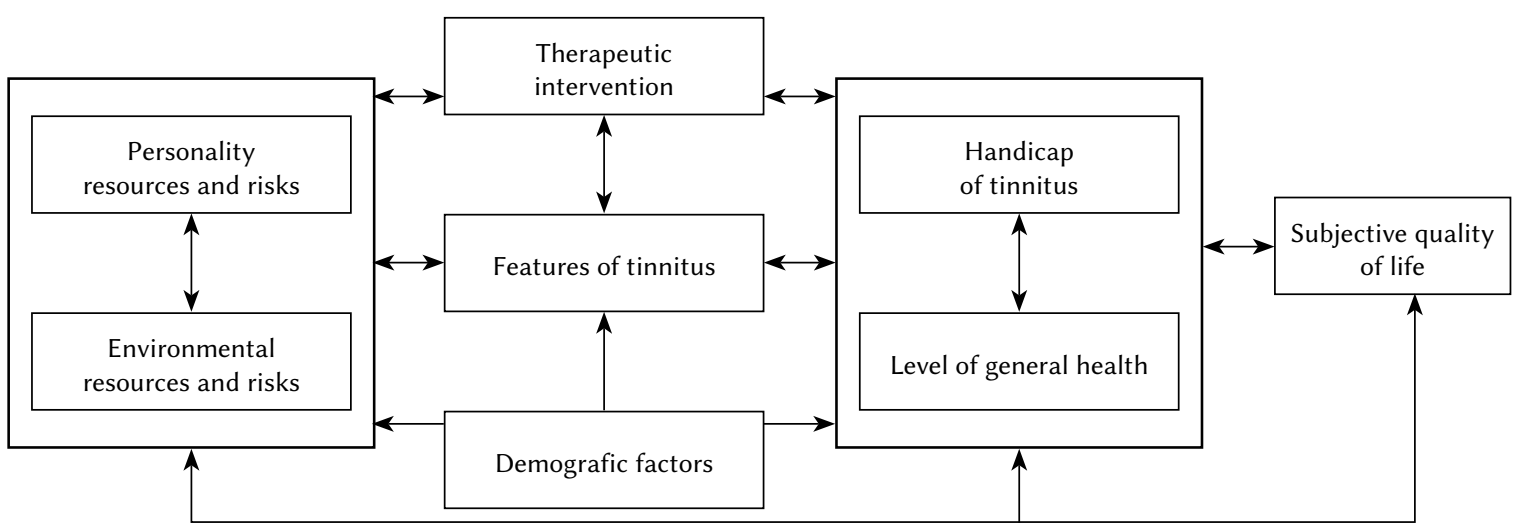

Health psychology and tinnitus

Figure 1. Model of variables presenting causes and consequences of tinnitus, important for research, diagnostic and therapeutic purposes.

rectangles in bold, i.e. the characteristics of tinnitus and the levels of tinnitus-related distress and general distress. However, both future research and everyday diagnostic practice should center around personality traits (considered both as resources and risk factors) and appropriate classification of environmental variables. After implementation of psychotherapy, a marker of its outcome and effectiveness in the form of a positive measure, e.g. subjective quality of life, will be required, apart from the negative measure of mental health, such as the psychiatric distress score used in our study. Potential direct and indirect associations between the variables are presented in Figure 1; as shown in the figure, relationships between some of the variables are likely bidirectional.

The questionnaires used in our study proved to be accurate and useful, not only for research purposes but also for everyday practice. However, also short, simple instruments for monitoring changes taking place in the course of therapy will be required after implementation of the intervention. The cognitive-behavioral approach seems to be an appropriate type of psychological therapeutic intervention, as we showed that the way of interpreting experienced symptoms may influence psychiatric distress of a patient, thus determining the outcome of therapy and rehabilitation. Therefore, we consider the use of individual and group therapy in the protocol of tinnitus treatment. Individual therapy should be offered particularly to patients presenting the highest levels of tinnitus-related distress and psychiatric distress. However, it should be remembered that although helpful in solving some problems, none of the instruments can replace establishing an appropriate relationship and communication with a patient.

\section{CONCLUSIONS}

Our study showed that tinnitus patients present a highly variable spectrum of needs; this points to the necessity of an individualized diagnostic and therapeutic approach. Nevertheless, we identified some common determinants of tinnitus-related distress and general distress. The diagnostic instruments used in our study (THI and GHQ-28) proved to be appropriate and identified a subset of tinnitus patients who required psychotherapeutic intervention due to the spectrum of presented ailments and the risk for distress. Moreover, our findings seem to confirm the accuracy of predefined determinants of tinnitus-related distress and general distress; nevertheless, the results of our study suggest that also personality-related resources and risk factors, as well as a positive measure of health, should be included in the research model of tinnitus-related distress. The complex situation of patients experiencing subjective signs of tinnitus points to a necessity of cooperation between specialists in laryngology and psychologists, as a vital component of multidisciplinary evaluation and the rehabilitation process.

\section{ENDNOTES}

1 The subjective character of tinnitus results from abnormal neural activity: tinnitus is observed despite the lack of acoustic stimulation of the external ear.

\section{REFERENCES}

Aksoy, S., Firat, Y., \& Alpar, R. (2007). The Tinnitus Handicap Inventory: a study of validity and reliability. International Tinnitus Journal, 13, 94-98.

Bartnik, G., \& Borawska, B. (2002). Program terapii szumów usznych metoda Tinnitus Retraining Therapy (TRT) [The Program of Tinnitus Retraining Therapy]. Warszawa: Instytut Fizjologii i Patologii Słuchu. 
Monika Klepas,

Eugeniusz Szymiec, Helena Sęk, Zofia

Obrębowska, Anna Sowińska
Erlandsson, S. I., \& Hallberg, L. R. (2000). Prediction of quality of life in patients with tinnitus. British Journal of Audiology, 34, 11-20.

Fabijańska, A. (1998). Badania epidemiologiczne szumów usznych i nadwrażliwości słuchowej na świecie i w Polsce [Epidemiological research of tinnitus in the world and Poland]. In S. Skarżyński (ed.). Szumy uszne i nadwrażliwość na dźwięki [Tinnitus and hypersensitivity of sounds] (pp. 35-41). Warszawa: Instytut Fizjologii i Patologii Słuchu.

Figueiredo, R. R., Azevedo, A. A., \& Oliveira Pde, M. (2009). Correlation analysis of the visual-analogue scale and the Tinnitus Handicap Inventory in tinnitus patients. Brazilian Journal of Otorhinolaryngology, 75, 76-79.

Henry, J. L., \& Wilson, P. H. (2001). Tinnitus: A self-Management Guide for the Ringing in Your Ears. Sydney: Allyn \& Bacon Incorporated.

Heszen, I., \& Sęk, H. (2007). Psychologia zdrowia [Heath psychology]. Warszawa: Wydawnictwo Naukowe PWN.

Kałużny, W., Durko, T., \& Pajor, A. (2004). Ocena wpływu szumów usznych na stan emocjonalny chorych na podstawie Kwestionariusza Ogólnego Stanu Zdrowia Goldberga [Impact of tinnitus on emotional state of patients according to General Health Questionnaire by Goldberg]. Otolaryngologia Polska, 58, 851-856.

Kałużny, W., Durko, T., \& Pajor, A. (2005). Wpływ szumów usznych na jakość życia w samoocenie chorych [Impact of tinnitus on quality of life in the selfreport]. Otolaryngologia Polska, 59, 271-276.

Karpiesz, L., Latkowska, E., Sarnictwa, I., \& Bartnik, G. (2012). Znaczenie współpracy lekarzy i psychologa w rehabilitacji pacjenta z szumem usznym [The role of cooperation between medical and psychological staff in the tinnitus rehabilitation]. Nowa Audiofonologia, 1, 112-115.

Klepas, M., Szymiec, E., Sęk, H., Sowińska, A., \& Obrębowska, Z. Psychologiczna charakterystyka pacjentów leczonych z powodu szumów usznych [Psychological characteristic of patients with tinnitus]. Otolaryngologia Polska [in press].

Kotyło, P., Macheta, K., \& Śliwińska-Kowalska, M. (2009). Ocena dokuczliwości szumów usznych i ogólnego stanu zdrowia chorych z szumami usznymi przed i po krótkotrwałej rehabilitacji metodą habituacji [Tinnitus annoyance and general health in patients with tinnitus before and after short-term rehabilitation on the basis of habituation]. Otolaryngologia Polska, 8, 23-27.

Kotyło, P., Merecz, D., Niebudek-Bogusz, E., \& Śliwińska-Kowalska, M. (2006). Program oceny i interwencji psychologicznej u pacjentów z szumami usznymi [Programm of the psychological diagnosis and intervention in patients with tinnitus]. Otolaryngologia Polska, 5, 189-194.
Newman, C. W., Jacobson, G. P., \& Spitzer, J. B. (1996). Development of the Tinnitus Handicap Inventory. Archives of Otolaryngology, Head and Neck Surgery, 122, 143-148.

Pajor, A., Józefowicz-Korczyńska, M., Durko, T., \& Ormezowska, E. (2009). Występowanie zaburzeń emocjonalnych u osób z szumami usznymi [Emotional disturbances in patients with tinnitus]. Otolaryngologia Polska, 8, 86-92.

Reich, G. E. (2000). American Tinnitus and Self-Help Groups. In: R. S. Tyler (ed.). Tinnitus Handbook (pp. 419-435). San Diego: Thomson Learning.

Robert, A., \& Dobbie, M. D. (2004). Tinnitus: Theory and management. In: J. B. Snow (ed.). Tinnitus: Theory and Management (pp. 1-6). Hamilton: BC Decker Inc.

Robinson, S. K., McQuaid, J. R., Viirre, E. S., Betzig, L. L., Miller, D. L., Bailey, K. A., \& Perry, W. (2003). Relationship of tinnitus questionnaires to depressive symptoms, quality of well-being, and internal focus. International Tinnitus Journal, 9, 97-103.

Snow, J. (2004). Specific tinnitus questionairres. In: J. B. Snow (ed.). Tinnitus: Theory and Management (pp. 244-254). Hamilton: BC Decker Inc.

Snow, J. B. (2004). Tinnitus: Theory and Management. Hamilton: BC Decker Inc.

Solly, I., \& Erlandsson, D. (2000). Psychological Profiles of Tinnitus Patients. In: R. S. Tyler (ed.). Tinnitus Handbook (pp. 25-53). San Diego: Thomson Learning.

Tyler, R. S. (2000). Tinnitus Handbook. San Diego: Thomson Learning.

Tyler, R. S. (2008). The Consumer Handbook on Tinnitus. San Diego: Auricle Ink Publ.

Zeman, F., Koller, M., Langguth, B., Landgrebe, M., \& Tinnitus Research Initiative database study, group (2014). Which tinnitus-related aspects are relevant for quality of life and depression: results from a large international multicentre sample. Health and Quality of Life Outcomes, 12, 7.

Zielińska-Bliźniewska, H., \& Olszewski, J. (2009). Szumy uszne a depresja [Tinnitus and depression]. Otolaryngologia Polska, 63, 20-23. 